\title{
The Role of Practice-Oriented Education in the Development of the Country's Economy
}

\author{
Zaripova Rimma \\ Kazan State Power Engineering University \\ Kazan, Russia \\ zarim@rambler.ru \\ Zinurova Rushania \\ Kazan National Research Technological University \\ Kazan, Russia \\ rushazi@rambler.ru
}

\author{
Porunov Alexander \\ Kazan National Research Technical University named after \\ A.N. Tupolev \\ Kazan, Russia \\ porunov_aa@mail.ru \\ Galyamov Roman \\ Kazan National Research Technological University \\ Kazan, Russia \\ sautp@kstu.ru
}

\author{
Stepanova Galina \\ Kazan Cooperative Institute (branch) of the Russian University of the Cooperation \\ Kazan, Russia \\ g.s.stepanova@mail.ru
}

\begin{abstract}
Current economic conditions require training of highly qualified specialists. Improving the quality of higher professional education is currently one of the urgent problems not only for Russia, but also for the entire world community. The solution to this problem is connected with the modernization of education, the optimization of methods and technologies for organizing the educational process. At the present stage of modernization of vocational education, production needs independent, creative, proactive, enterprising specialists who are able to make a profit, propose and develop ideas, find innovative solutions and implement cost-effective projects.

The article discusses a practice-oriented approach to learning in an educational institution; application of practice-oriented technologies; gradual formation of professional competencies of the student's personality in accordance with educational standards; the process of forming professional competencies among students of a technical university is analyzed.
\end{abstract}

Keywords: education, practice, practice-oriented approach, competencies, students

\section{INTRODUCTION}

Globalization leads to worldwide integration in various In almost all regions of Russia, a certain part of university graduates get jobs outside their specialty. One of the reasons is that employers need ready-made specialists with work experience, and a graduate usually does not have it. In the training of specialists of any profile, an urgent problem is the problem of strengthening the practical part of the training of future specialists [1].

Modern employers consider the knowledge, skills and abilities of graduates in the context of abilities and willingness to effectively apply them in practice, meet the quality standards of industry and regional service markets. One way to solve this problem is to implement a practice-oriented approach. This approach to learning is aimed, firstly, to bring the educational institution closer to the real needs of practice and life. Secondly, it allows students to create conditions for the targeted formation of competitiveness of future workers and employees.

The methodological aspect of satisfying this production need and involving future specialists in the process of social transformation of society is the professional development of students [2-4]. The solution to this problem at the university level is possible by making certain changes to the curriculum and training program for future bachelors and masters. The introduction and widespread use of new forms and methods of training (trainings, a workshop, group work, design methods, case studies, etc.) is possible due to the spread of new approaches to ensuring the quality of bachelor training determined by the employer.

The application of a practice-oriented approach should begin at school and purposefully transfer to the system of higher professional education and be the main method of 
training at this stage of the education system. Any educational technology is the embodiment of a certain strategy. The introduction of a practice-oriented approach in the educational process of the university is due to the need to search for adequate educational technologies, a combination of means and methods of teaching and development of students that allow them to successfully achieve goals.

The main goal of the practice-oriented approach in education is to build an optimal model (technology) that combines the application of theoretical knowledge in solving practical issues related to the formation of professional competencies of a specialist [5-8]. The model of such professional training should be closely linked with the goals of the activities of industry organizations and regional services markets, the current and future tasks of economy as a whole, ensuring high management efficiency and making the necessary profit.

\section{MATERIALS AND METHODS}

Provisions of the system approach acted as the fundamental methodological prerequisite in this research [5]. Within this approach the education system should be considered as opened, suffering influence of the environment (the main directions of the state and regional growth, world scientific trends, and most of all the needs of employers, as the main objective of training at the university is obtaining qualification, which allow to carry out qualitatively certain labour operations, which a person who does not have the corresponding education cannot carry out [6].

There are several approaches to practice-oriented education in the higher education system. Some authors associate a practice-oriented education with the organization of a student's educational, industrial and undergraduate practice in order to immerse him in a professional environment, correlate his idea of a profession with the requirements of a real business and recognize his own role in social work. Other authors consider the most effective implementation of professionally-oriented teaching technologies that contribute to the formation of personal qualities that are significant for future professional activities, as well as knowledge and skills that ensure high-quality performance of functional duties in the chosen specialty. Some authors associate the formation of a practice-oriented education using contextual studies of specialized and non-core disciplines.

Monitoring the effectiveness of the use of practice-oriented teaching methods in the preparation of students should be carried out according to specially designed tests and questionnaires, which allows people to evaluate the person's knowledge, skills and professional qualities. Full-fledged professional training of engineers is impossible without the provision of competent and practice-oriented approaches to training, which can be implemented with a reasonable combination of fundamental education and professionalapplied training. In the process of mastering the educational program, students receiving not only theoretical knowledge, but also practical skills, are guaranteed by several components of training.
Firstly, the mandatory inclusion of practitioners in the teaching staff. Federal educational standards establish what proportion of the total number of university employees implementing the educational program should be employees of organizations whose activities are related to the profile of this program, and the requirements for the experience of such specialists. Moreover, universities, as a rule, are not limited to these minimum values now. About half of teachers in master's programs are practical scientists at many universities.

Secondly, many educational programs currently include not only a certain number of hours of practical training, but actually complete immersion in the specialty before graduation. Previously, only in the fourth year students began to engage in scientific work in organizations with which the university cooperates, now this process occurs earlier. It is necessary to introduce an energetic learning style, especially since the use of modern technologies allows students to quickly and efficiently master educational programs [7-10].

The master's program should be aimed at obtaining students' knowledge for the real needs of the practice and economy of the country, therefore, when deciding on the opening of new master's programs, universities should take this into account. In Russia, the Master of Science is a specialist with a higher professional education, who has a deep knowledge of fundamental sciences, as well as special knowledge and skills at a level sufficient for research, scientific production, scientific and pedagogical activities.

Adopting the Bologna education system, Russian higher education institutions should take into account the experience of European countries, monitor and compare the progress of educational reforms. For example, the British Master's programs, unlike the Russian ones, do not contain disciplines aimed at improving the general culture of the student, but focus exclusively on the issues of professional training of a specialist in a particular field. Feedback from students, alumni, employers and professional communities has a significant impact on the structure, content and demand for Master's programmes, is one of the most important areas of work of British universities and one of the essential factors ensuring the high quality of British Master's programmes.

In the USA, a great deal of attention is paid to higher technical education in order to provide companies with highly qualified personnel. The ideal of the multistage system of the USA, in the process of its development it has absorbed the best world experience, transformed it in relation to its social and economic conditions and has become a standard to which the countries of Western Europe and Japan aspire [11-15]. Higher professional education in the United States is twostage: the first stage ends with a bachelor's degree and the second with a master's degree. The second level is designed for 1-2 years of study after two years of practical experience. The U.S. curriculum is designed to provide Masters with all the tools necessary to continue their successful work in the workplace, while providing Masters with an exceptional degree of professional flexibility. The training is based on the fact that the acquired knowledge is ready for practical application. The determining factor in training specialists with higher education in the USA is the employer. Higher 
"action learning" is to bridge the gap between what a person knows and what he does. Therefore, an important task is to determine technology activities for the formation of each competence from the above list. Modern technology activities and teaching methods include: design methods and technologies for research activities; imitation, role-playing and expert games; trainings, laboratory workshops; different practices; group discussions, presentations, interdisciplinary seminars, etc.

Traditional and innovative technologies of educational activities should, whenever possible, use modern information and communication technologies that increase the practical orientation of the educational process, as also take into account the individual characteristics of students. The formation of competence is a process, and the level of its formation is a characteristic that varies over time. The development of the components of a separate competency usually occurs gradually [23]. For example, in junior courses at university, a student acquires knowledge and skills, and then skills in the field of the studied disciplines of the humanitarian and natural-science cycles. In senior courses, they become in demand in the course of studying general professional and special disciplines, passing the practice of training and production practices, and completing course and diploma projects.

The essence of practice-oriented teaching is the development of students' educational programs not in the audience, but in real life, the formation of students' professional competencies by performing real practical tasks during study time in leading specialized organizations. The task of the university environment should be to assist students in individual self-expression, therefore, it is necessary to provide certain opportunities for the disclosure of abilities and meet the interests of students [2]. A knowledge system is needed that promotes the development of interest in the search for that person, who will subsequently form a highly qualified competent specialist who can solve any problems associated with his professional activity.

The entire educational process can be divided into several stages associated with the gradual accumulation of professional competencies and personal qualities by a student.

The first stage (1 course) - adaptive, provides familiarity with the basics of the future profession, the specifics of the educational process. The most effective at this stage are students undergoing summer educational and practical training, during which individual interviews with students are conducted in order to identify the student's abilities and assist in choosing the direction of independent work.

The second stage ( 2 year) is the stage of mastering the basics of the future profession, where professional adaptation, the accumulation of educational, didactic and normative knowledge take place. By the end of the second year, students should prepare small educational projects and form a circle of their interests in future professional activities. In the second year, students take additional courses, at the end of which they receive certificates of assignment of a working profession to them. This is important at this stage, as in the future the individual, they are manifested and verified only in the process of a student performing a series of actions. The goal of 
Creating a practice-oriented educational process will allow bringing content of academic disciplines very accurately of student's future profession, create a holistic educational process and create the conditions for targeted formation of the competitiveness of future workers. Society needs a personality capable of solving non-standard tasks in non-standard situations, is capable of self-development, self-education, is able to successfully position itself in the labor market, focusing on socially significant priorities.

The implementation of a practice-oriented approach contributes to the improvement of existing educational programs and technologies for creating conditions for the training of specialists with a qualitatively new level of professional competencies, ready for professional activities in modern conditions. The task of teachers is to form students' practical experience of professional activity on the basis of a specific organization; master professional and general competencies by type of professional activity; check the possibilities of independent work of future specialists in a specific organization.

Practice-oriented training is one of the effective tools for formation of professional competencies and personal-active training of students in technical specialties. It has a systematic effect on educational process and allows students to comprehensively implement tasks of theoretical and practical training, creative development and education of a specialist, as well as acquisition of professional skills by students.

The main way to improve the educational process in a technical university is not to increase the amount of knowledge transferred, but to develop the skills of their scientific, professional understanding. This is what contributes to the formation and development of professional competence of students' technical specialties. Practice-oriented education involves the study of fundamental disciplines traditional for Russian education in combination with applied disciplines of technological or social orientation. Renewed education should play a key role in preserving fundamental science and developing the applied sciences necessary for the sustainable development of Russian society. Without the appeal of vocational education to practice-oriented teaching
A practice-oriented approach in an educational institution should be applied by the teaching staff from the first days of training and further contribute to further phased formation of professional competencies of the student's personality. Firstly,

\begin{abstract}
the student adapts to the educational process. This forms an understanding of nature and social significance of his future

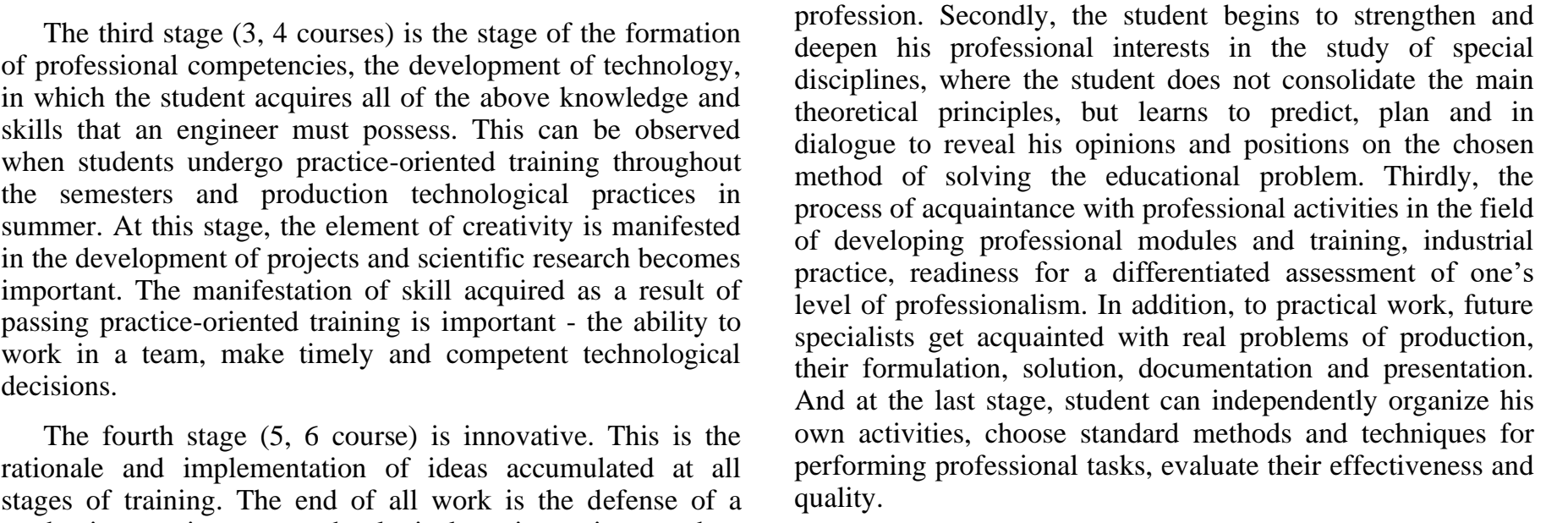

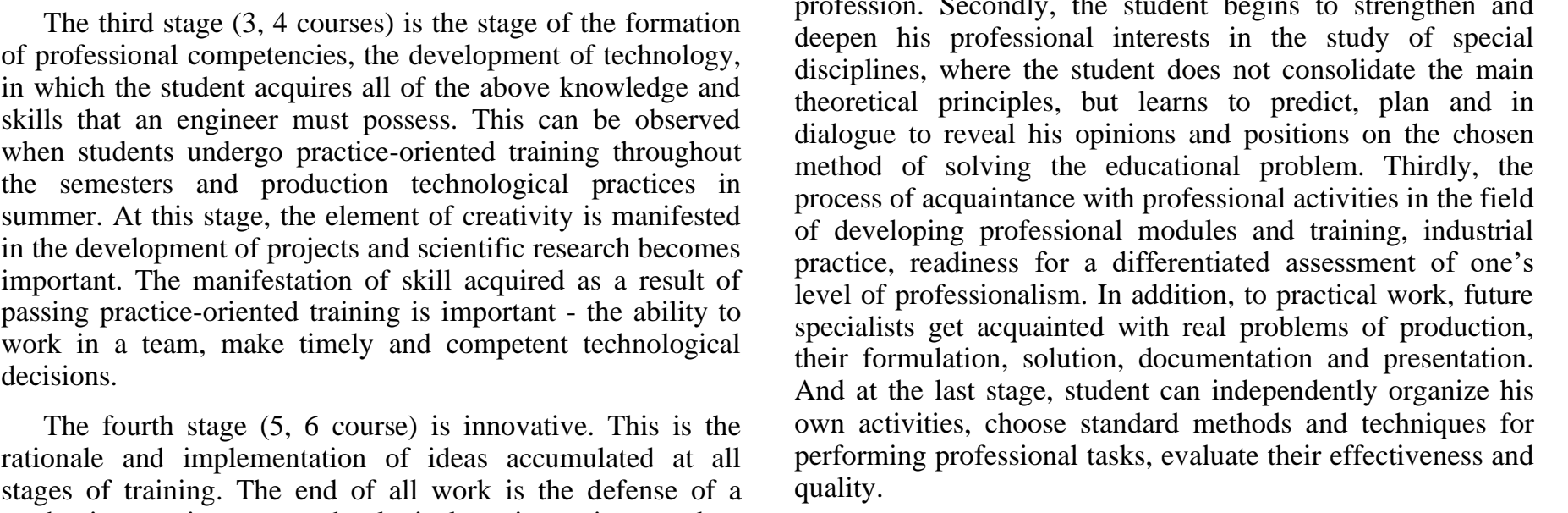

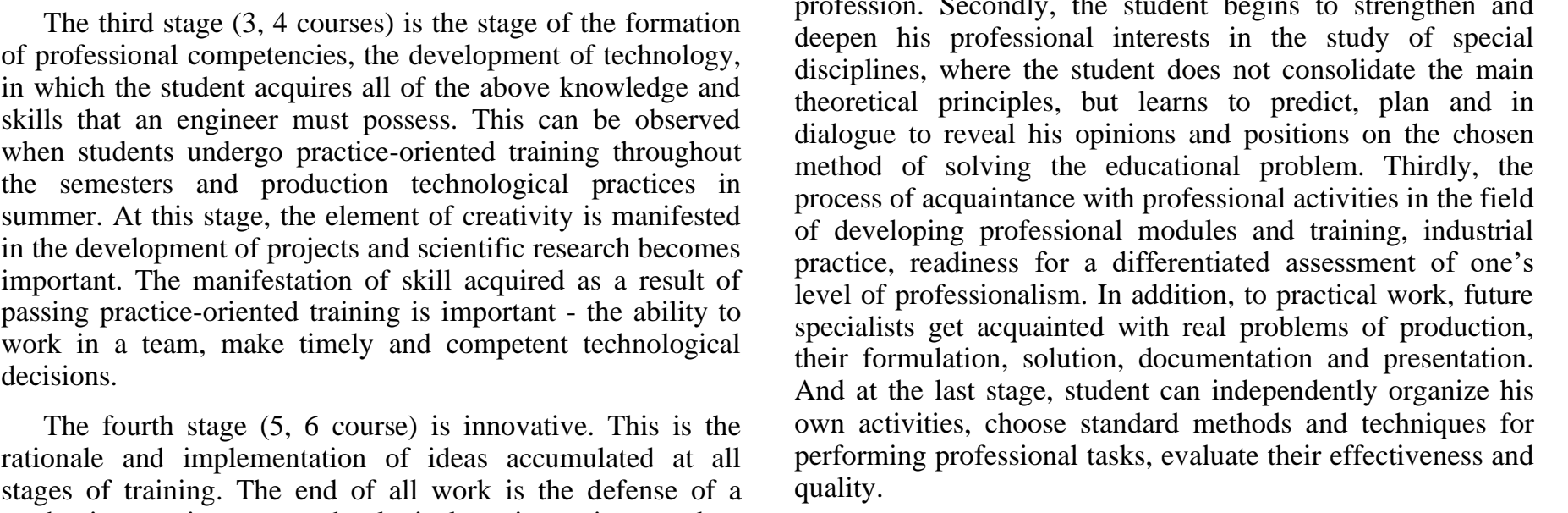

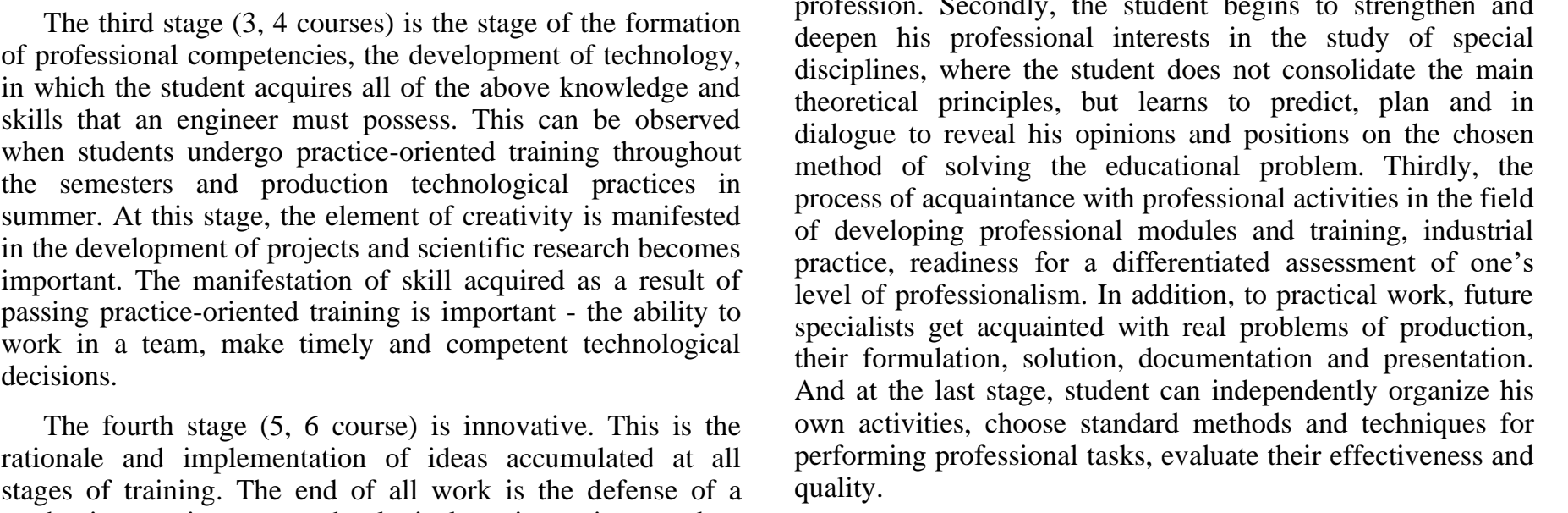

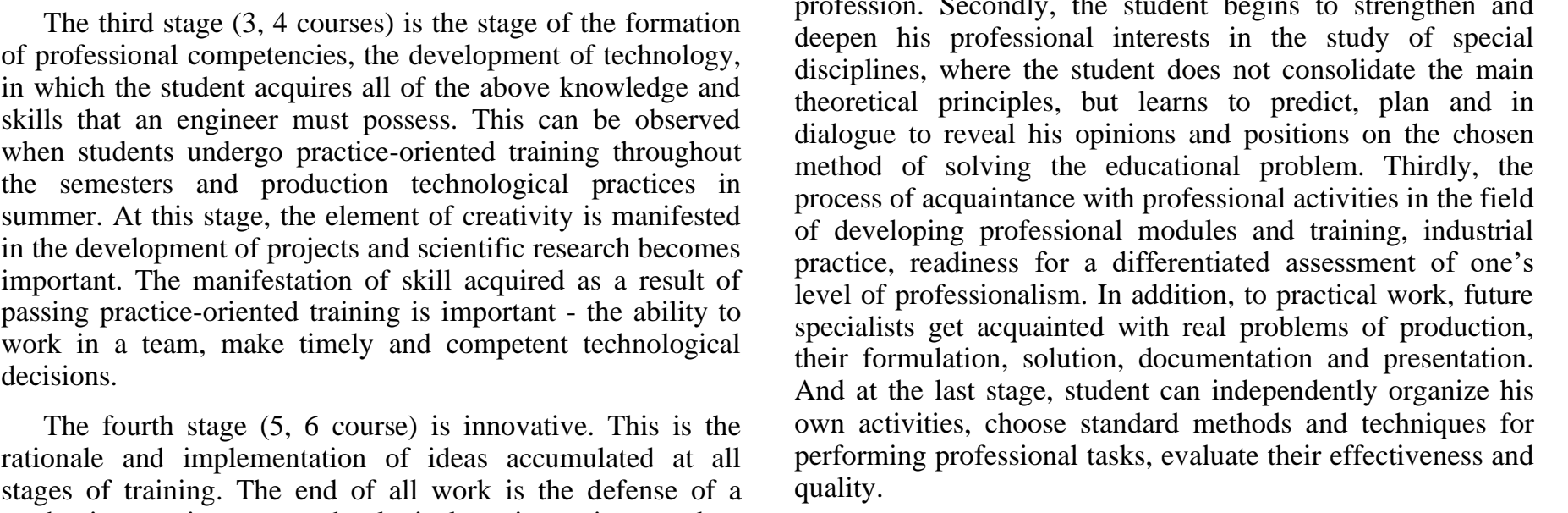

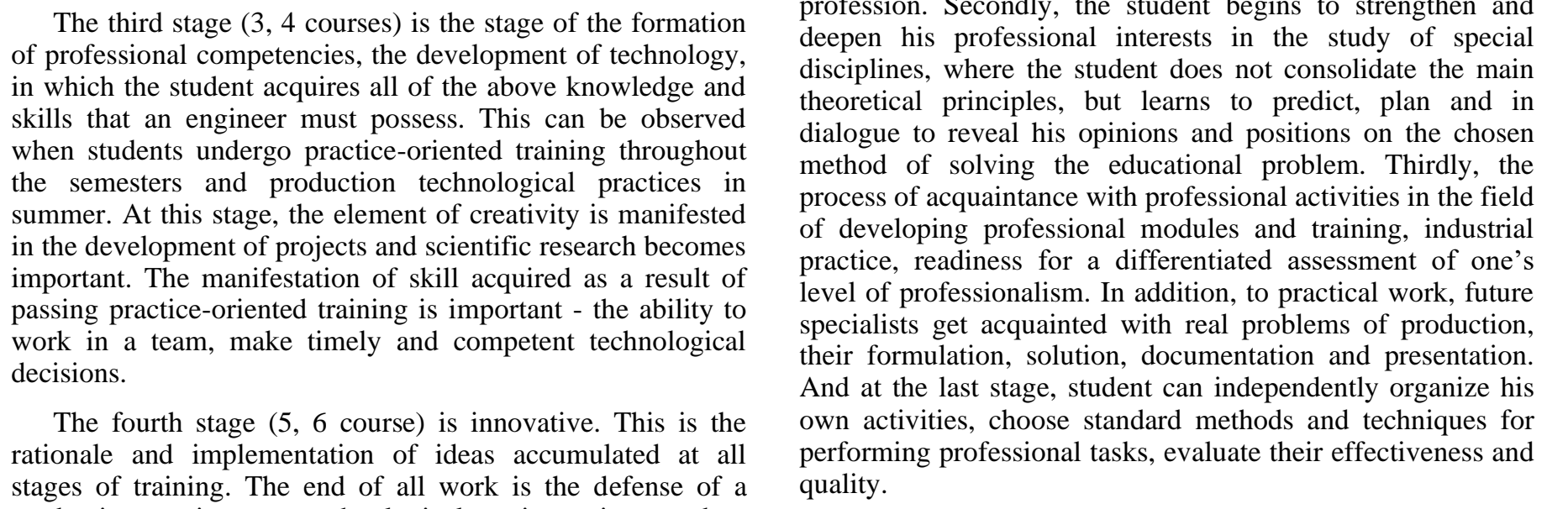

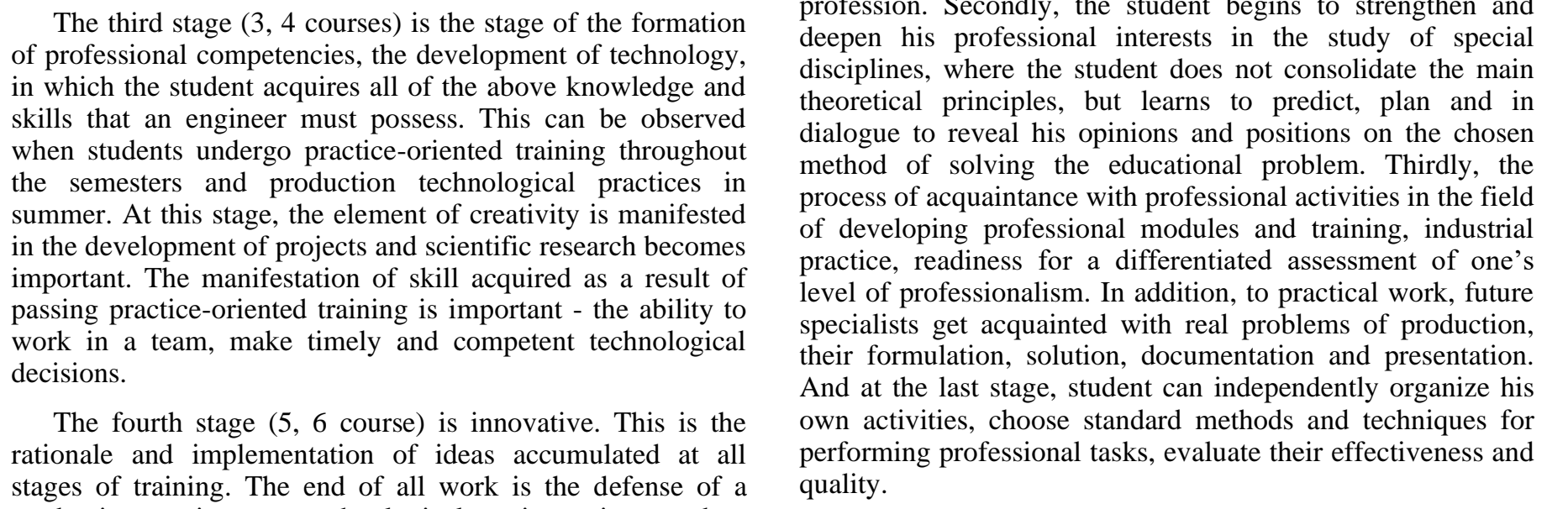

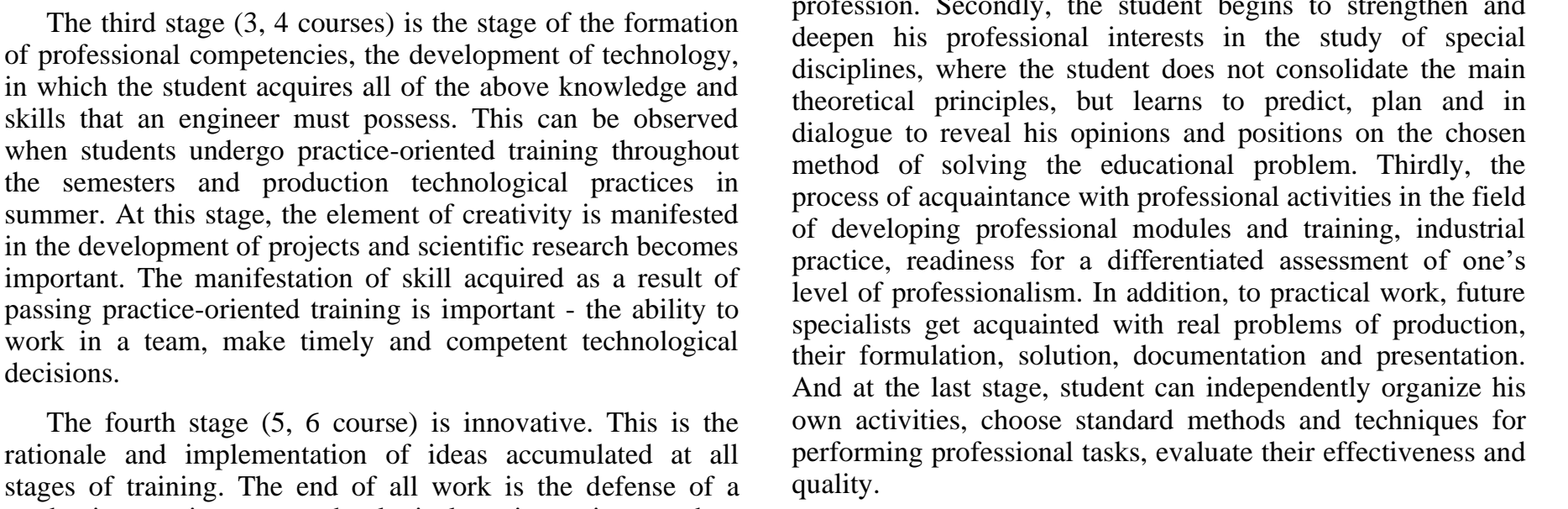

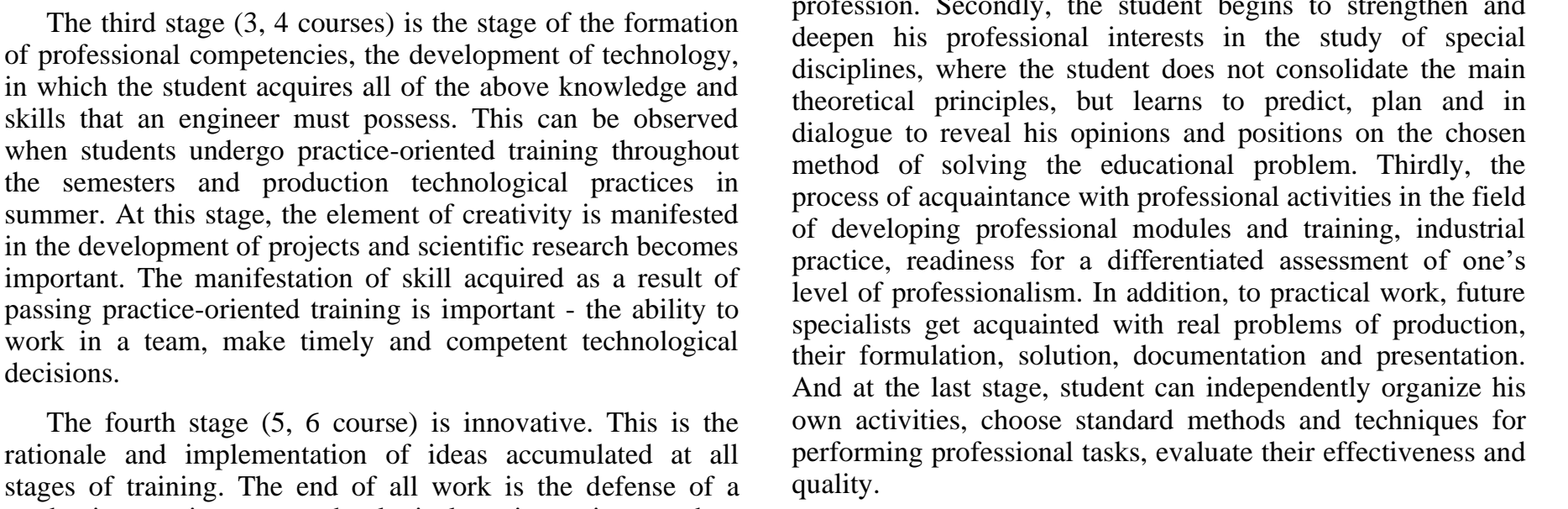

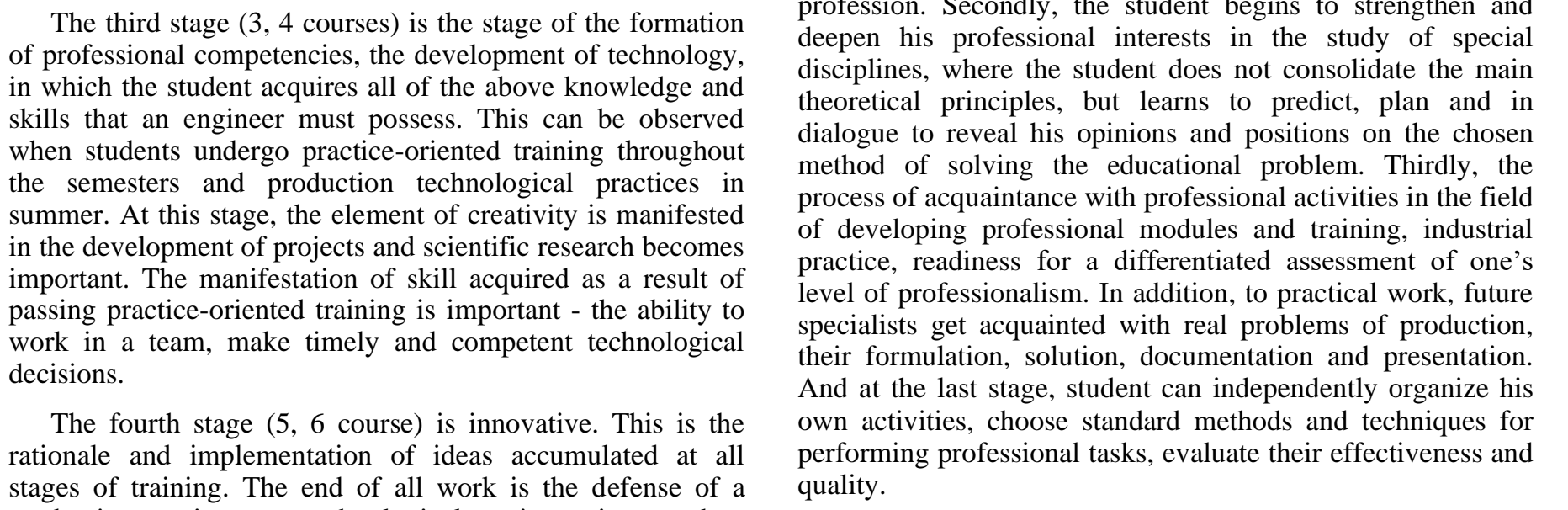

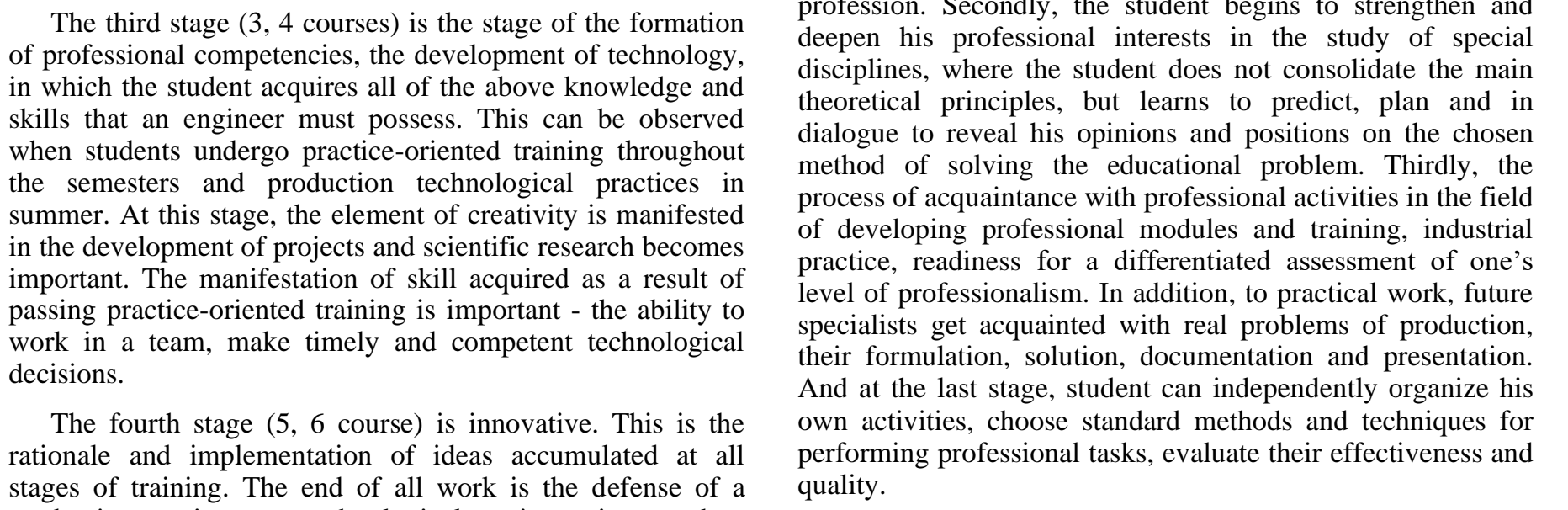

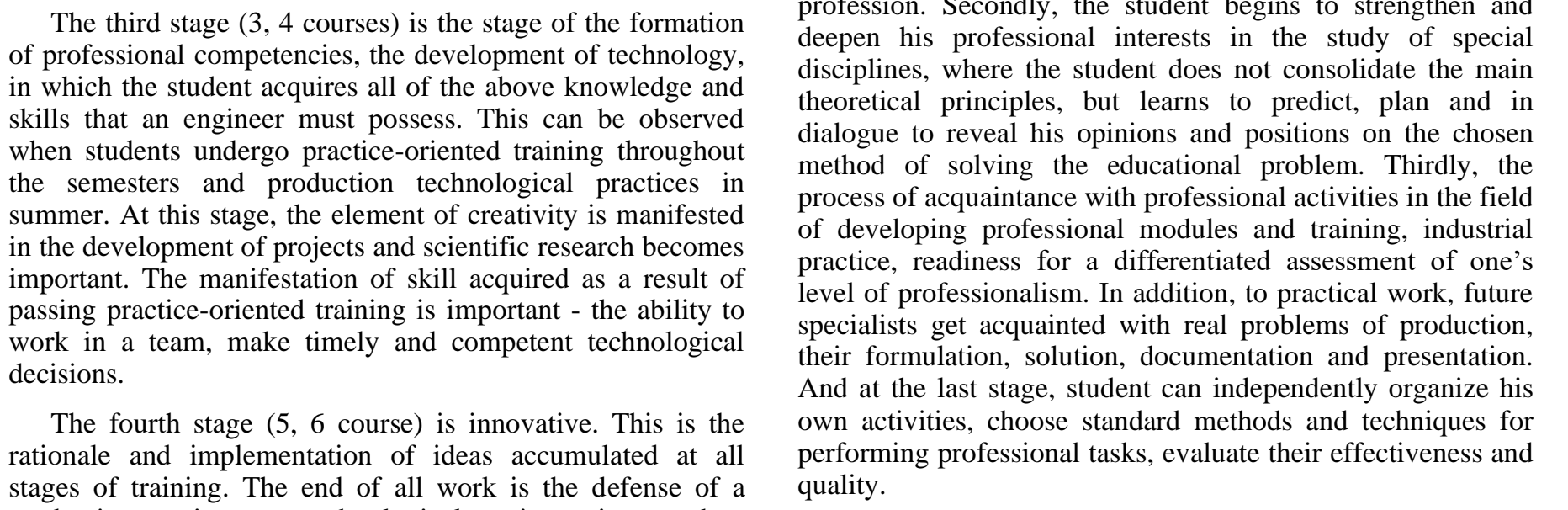

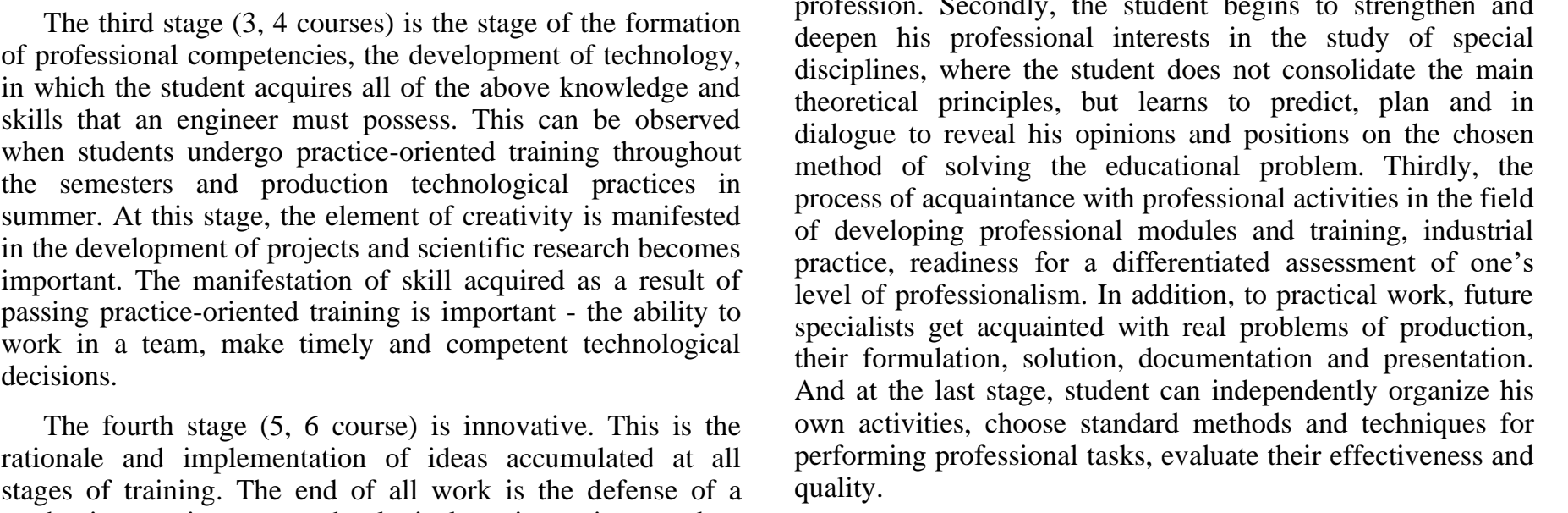

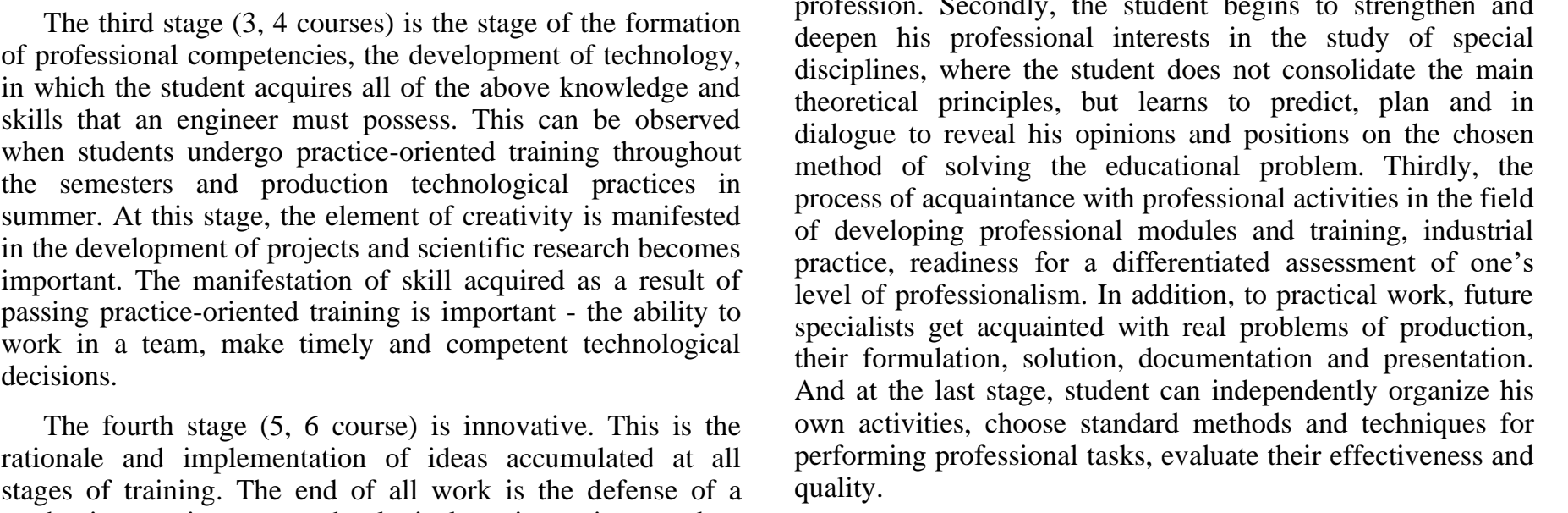

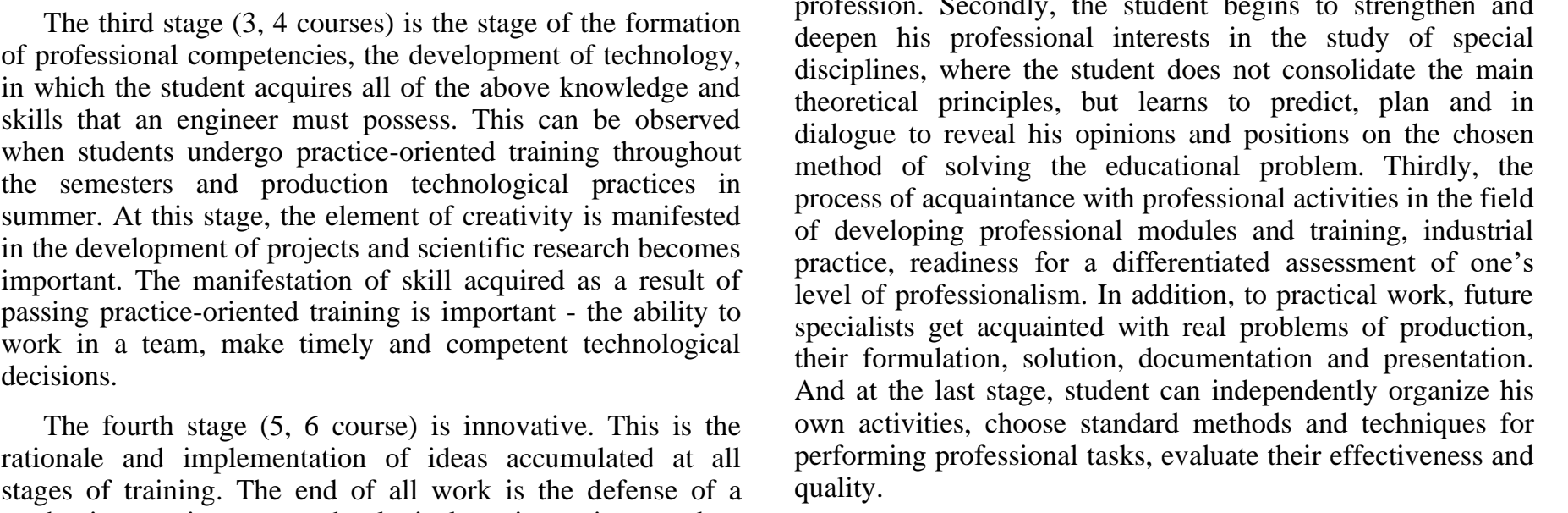

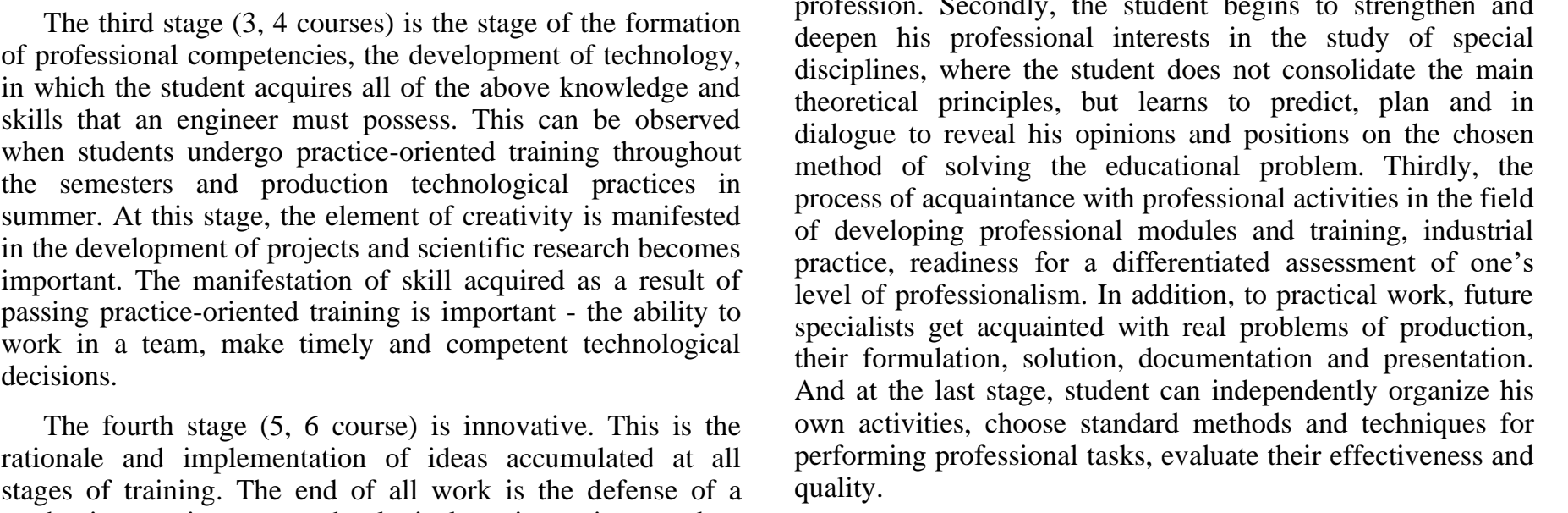
rofessim to fulfill his duties help him tedge will

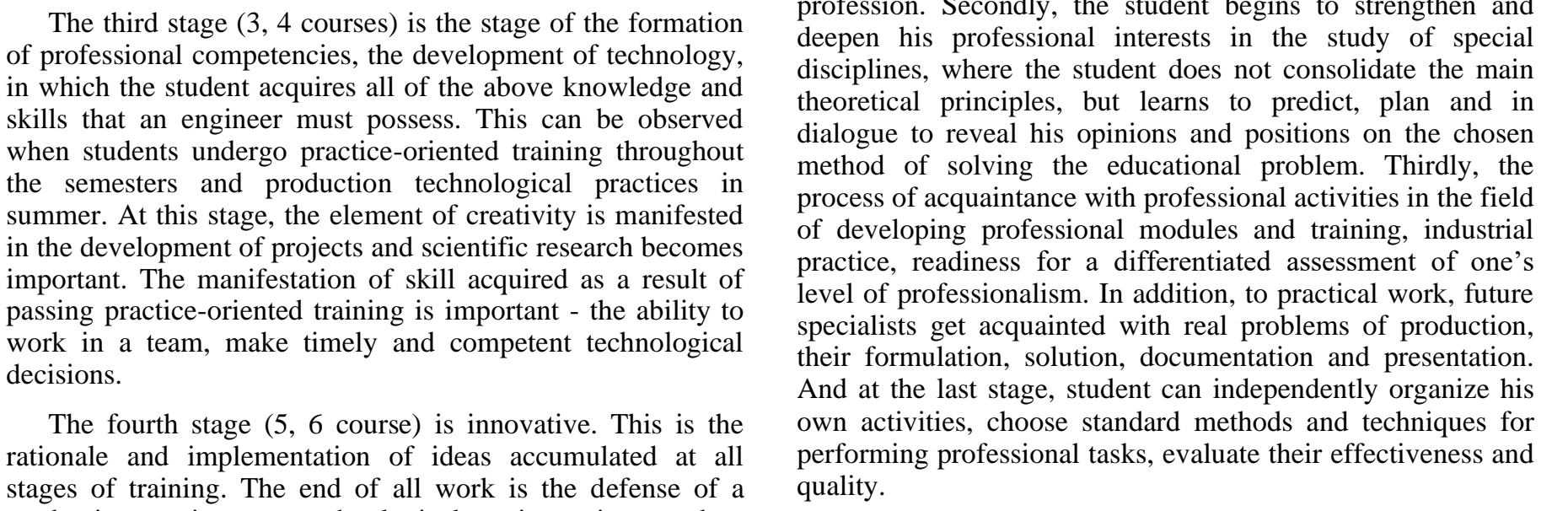
by practice-oriented training, since it significantly contributes implementation of practical tasks compiled by teachers of the graduating department;

4. Development of practical skills among students-trainees

5. Desire to achieve recognition in the work through the 6. Determination by employers of the potential of future There are several approaches to practice-oriented learning in the higher education system. The first approach connects
him with the organization of the educational, production and undergraduate practice of the student in such way that student is immersed in a professional environment. Adherents of the system of professionally-oriented technologies, including context-based learning technologies.

\section{CONCLUSION}

(n)
graduation project on technological topics using modern

Thus, the process of formation of professional institutions, organizations and best practices of their specialists by transferring from "hand to hand" effective skills, echnologies and schemes developed by them in practice; 3. Deepening and consolidating knowledge gained in the

The main objectives of practice-oriented training are:

2. Studying the principles of work of enterprises, competencies, the formation of students as future specialists is 
[11] M. Morrison, "Why fresh graduates are not ready for the world of work - yet," Rapidbi, vol. 1, 2019, nhttps://rapidbi.com/why-freshgraduatesare-not-ready-for-the-world-of-work-yet/.

technologies, it is quite problematic to complete the tasks development of the country's economy. Thus, practical orientation and dialogue allow students to acquire the necessary minimum professional skills, organizational experience, system of theoretical knowledge, professional mobility and competence, which meets the educational standard and makes our graduates competitive.

\section{REFERENCES}

[1] R.S. Zaripova, O.A. Pyrnova, "Features and development trends of modern engineering education," Modern studies of social problems, vol.9(8-2), 2018, pp. 43-46.

[2] O.A. Pyrnova, R.S. Zaripova, "Artificial Intelligence Technologies in Education," Russian Journal of Education and Psychology, vol. 10(3), 2019, pp. 41-44

[3] R.S. Zaripova, V.V. Halueva, "Analysis of the functioning of the student knowledge assessment system," Russian Journal of Education and Psychology, vol. 10(5), 2019, pp. 31-35.

[4] A.E. Krivonogova, R.S. Zaripova, "Modern information technologies and their application in the field of education," Russian Journal of Education and Psychology, vol. 10(5), 2019, pp. 44-47.

[5] K. Gordon, C. Chen, "What Is the Systems Approach?," Interfaces vol. 6(1-1), 1975, pp. 32-37, https://www.jstor.org/stable/25059250.

[6] T.N. Kisel, "Cooperation of universities and employers within the preparation of graduates for their work in organizations," International Scientific-Practical Conference on Business Cooperation (ISPCBS 2019) Advances in Economics, Business and Management Research, vol. 90, 2019, pp. 341-344.

[7] R.S. Zaripova, "Global trends in modern education," in NovaUm.Ru, vol. 13, 2018, pp. 232-234.

[8] Yu.K. Sitnikov, S.Yu. Sitnikov, "Theory, computer model, laboratory setup," Scientific notes ISGZ, vol. 1, 2015, pp. 494-499.

[9] E.R. Galiullina, R.S. Zaripova, "Digital games as a way of learning," Scientific notes ISGZ, vol. 17(1), 2019, pp. 126-129.

[10] Z.N. Shirmamedova, R.S. Zaripova, "The role of open electronic educational resources in the modern educational information space," Scientific notes ISGZ, vol.17(1), 2019, pp. 536-539.

[12] F. Carr, "A third of employers are unhappy with graduates' attitude to work," The Telegraph, vol. 7, 2017, https://www.telegraph.co.uk/education/2017/07/11/thirdemployersunhappy-graduates-attitude-work/

[13] D. Docherty, Universities must produce graduates who are ready for any workplace, The Guardian, https://www.theguardian.com/highereducationnetwork/2014/may/22/universities-must-producegraduates-who-areready-for-workplace

[14] M. Riklan, "Students Think They're Ready For The Corporate World; Employers Disagree," Forbes, vol. 6, 2018, https://www.forbes.com/sites/forbescoachescouncil/2018/06/25/students -think-theyre-ready-for-the-corporate-worldemployersdisagree/\#13846fd35c45.

[15] Strada-Gallup 2017 College Student Survey, https://news.gallup.com/reports/225161/2017-strada-gallupcollegestudent-survey.aspx.

[16] C. Paine, "What does training look like in an unknown future?," $\begin{array}{llll}\text { Training } & \text { Journal, } & \text { vol. } & 4,\end{array}$ https://www.trainingjournal.com/articles/feature/work-ready-graduate.

[17] V. Callier, R.H. Singiser, N.L. Vanderford, "Connecting undergraduate science education with the needs of today's graduates," Journal List, vol. 3; 2014, PMC4304216.

[18] Junior Achievement USA, Are Students Prepared for theWorkplace? New Tools for a New Generation, A JA Education Blueprint Initiative.

[19] T. Schultz, Investment in Human Capital: The Role of Education and of Research,1971.

[20] C. DuPre, K. Williams, "Undergraduates' Perceptions of Employer Expectations," Journal of Career and Technical Education, vol. 26(1), 2011, https://ejournals.lib.vt.edu/JCTE/article/view/490/676.

[21] A.A. Shakirov, R.S. Zaripova, "Teaching computer modeling using interactive environments", International Journal of Advanced Studies in Education and Sociology, vol. 1, 2019, pp. 56-59.

[22] S.Yu. Sitnikov, Yu.K. Sitnikov, "Industrial packages of applied programs in the educational process," Bulletin of KSEU, vol. 22, 2014, pp. 339-345. 